\title{
On the Seidel Energy of Certain Mesh Derived Networks
}

\author{
Sophia Shalini G. B., Anwar Saleh, Dhananjayamurthy B.V
}

Abstract: The energy of graph $G$ is defined as the sum of the absolute values of eigenvalues of the adjacency matrix $A(G)$. The manual calculation of energy of graphs consumes several man hours. In this paper, we use MATLAB to generate the Seidel matrix and hence calculate the Seidel energy of some mesh derived networks.

Keywords: Seidel matrix, Seidel energy, Grid, Cylinder, Torus, Extended grid. AMS classification. 05C15,05C50

\section{INTRODUCTION}

Let $\mathrm{G}=(\mathrm{V}, \mathrm{E})$ be an undirected simple graph with $\mathrm{n}$ vertices $\left\{v_{1}, v_{2}, \ldots ., v_{n}\right\}$. The adjacency matrix $A(G)=\left[a_{i j}\right]$ is defined as

$$
a_{i j}=\left\{\begin{array}{l}
1, \text { if } v_{i} v_{j} \in E(G) \\
0, \text { otherwise }
\end{array}\right.
$$

Let $\lambda_{1}, \lambda_{2}, \ldots \lambda_{n}$ be the eigenvalues of $A(G)$ assumed in the non-increasing order. Since the matrix $A(G)$ is a real symmetric matrix, the eigenvalues of the graph $G$ are real and their sum is equal to zero. The concept of energy of graphs was introduced by Ivan Gutman in the year 1978 [5]. The energy of a graph $G$ is defined as the sum of the absolute values of eigenvalues of $A(G)$. That is,

$$
E(G)=\sum_{i=1}^{n}\left|\lambda_{i}\right|
$$

For further facts and the results on the energy of graphs we refer the following papers [3, 6, 7]. The various bounds for the energy of a graph and the characteristics of it have been established in $[1,4]$. The Seidel energy of a graph G was defined by Willem.H. Haemers [10] in 2012. Latterly the Laplacian energy of a gridbased networks was calculated by Bharathi Rajan et al. [2]. Followed by this, Rajesh Kanna M.R. et al. have calculated the maximum degree energy of certain mesh derived networks [8]. Also, Pradeep Kumar et al. calculated the Harary energy of some of the networks using MATLAB [9]. From the review of the above-mentioned papers, we calculate the Seidel energy of some of the graph networks such as Grid, Cylinder, Torus and Extended grid.

Revised Manuscript Received on December 30, 2019.

* Correspondence Author

Sophia Shalini G.B., Department of Mathematics, Mount Carmel College, Bangalore-58, India sofi.saranya920@gmail.com

Anwar Saleh, Department of Mathematics, College of Science, University of Jeddah, Saudi Arabia Asaleh1@uj.edu.sa

Dhananjayamurthy B.V., Department of Mathematics, NITTE Meenakshi Institute of Technology, Yelahanka, Bangalore-64, India. dmgyashas@gmail.com

(C) The Authors. Published by Blue Eyes Intelligence Engineering and Sciences Publication (BEIESP). This is an open access article under the CC BY-NC-ND license (http://creativecommons.org/licenses/by-nc-nd/4.0/)

\section{SEIDEL ENERGY}

Consider a simple graph $\mathrm{G}$ of order $\mathrm{n}$ and size $\mathrm{m}$. The Seidel matrix of $\mathrm{G}$ is the $n \times n$ matrix denoted by $S(G)=\left[s_{i j}\right]$, where

$$
s_{i j}= \begin{cases}-1, & \text { if } v_{i} v_{j} \in E \\ 1, & \text { if } v_{i} v_{j} \notin E \\ 0, & \text { otherwise }\end{cases}
$$

Let $\mu_{1}, \mu_{2} \ldots \mu_{n}$ be the eigenvalues of the Seidel matrix $\mathrm{S}(\mathrm{G})$. The characteristic polynomial of $\mathrm{S}(\mathrm{G})$ denoted by $f_{n}(G, \mu)=\operatorname{det}(\mu I-S(G))$. The Seidel energy of a graph $\mathrm{G}$ is defined as $S E(G)=\sum_{i=1}^{n}\left|\mu_{i}\right|$.

\section{SEIDEL ENERGY OF SOME STANDARD GRAPH NETWORKS}

\section{A. Grid Graph $q(\mathbf{m}, \mathbf{n})$}

The grid network $\mathscr{q}(\mathrm{m}, \mathrm{n})$ is defined as the Cartesian product $P_{m} \times P_{n}$ of undirected paths $P_{m}$ and $P_{n}$. The eigenvalues of the graph do not depend on the labeling of its vertices. Nevertheless, we follow a specific way of labeling so that the Seidel matrix has a pattern which is similar for any order. Here we number the vertices in vertical order as shown in Fig.1.

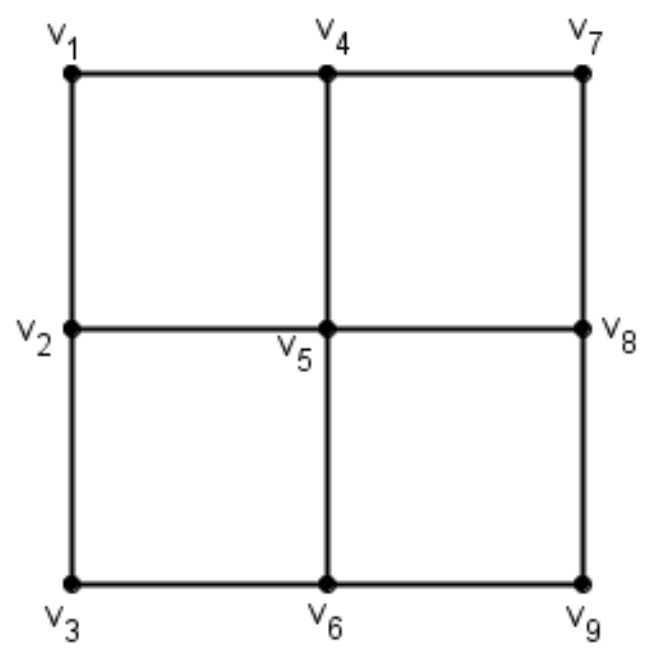

Fig 1. Gridgraph(3,3)

The Seidel matrix of 3x3 grid is given by 


\section{On the Seidel Energy of Certain Mesh Derived Networks}

$$
\begin{gathered}
S=\left[\begin{array}{lll}
B & C & D \\
C & B & C \\
D & C & B
\end{array}\right], \text { where } B=\left[\begin{array}{ccc}
0 & -1 & 1 \\
-1 & 0 & -1 \\
1 & -1 & 0
\end{array}\right], \\
C=\left[\begin{array}{ccc}
-1 & 1 & 1 \\
1 & -1 & 1 \\
1 & 1 & -1
\end{array}\right], D=\left[\begin{array}{lll}
1 & 1 & 1 \\
1 & 1 & 1 \\
1 & 1 & 1
\end{array}\right]
\end{gathered}
$$

In general, the Seidel matrix of $\mathscr{q}(\mathrm{m}, \mathrm{n})$ can be written as

$$
\begin{aligned}
S & =\left[\begin{array}{ccccccc}
B & C & D & . & . & \ldots & D \\
C & B & C & D & . & \ldots & D \\
D & C & B & C & D & \ldots & D \\
\cdot & . & . & . & . & \ldots & . \\
\cdot & . & . & . & . & \ldots & C \\
D & D & . & . & . & C & B
\end{array}\right] \text {, where } \\
B & =\left[\begin{array}{ccccccc}
0 & -1 & 1 & . & . & \ldots & 1 \\
-1 & 0 & -1 & 1 & . & \ldots & 1 \\
1 & -1 & 0 & -1 & 1 & \ldots & 1 \\
\cdot & . & . & . & . & \ldots & . \\
\cdot & . & . & . & . & \ldots & -1 \\
1 & 1 & . & . & . & -1 & 0
\end{array}\right]
\end{aligned}
$$$$
C=\left[\begin{array}{ccccccc}
-1 & 1 & . & . & . & \ldots & 1 \\
1 & -1 & 1 & . & . & \ldots & 1 \\
1 & 1 & -1 & . & . & \ldots & 1 \\
. & . & . & . & . & \ldots & . \\
. & . & . & . & . & \ldots & 1 \\
1 & 1 & . & . & . & 1 & -1
\end{array}\right],
$$

$$
D=\left[\begin{array}{ccccccc}
1 & 1 & . & . & . & \ldots & 1 \\
1 & 1 & 1 & . & . & \ldots & 1 \\
1 & 1 & 1 & . & . & \ldots & 1 \\
\cdot & . & . & . & . & \ldots & . \\
\cdot & . & . & . & . & \ldots & 1 \\
1 & 1 & . & . & . & 1 & 1
\end{array}\right]
$$

The MATLAB program given below generates the Seidel energy of a grid $\mathfrak{q}(\mathrm{m}, \mathrm{n})$

function energygrid(m,n)

$\mathrm{n}=3$;

$\mathrm{m}=3$;

$\mathrm{v}=\mathrm{m} * \mathrm{n} ;$

$\mathrm{A}=$ ones $(\mathrm{v})$;

for $a=1: n: v$ for $b=a: a+(n-2)$

$\mathrm{A}(\mathrm{b}, \mathrm{b}+1)=-1$;

$A(b+1, b)=-1$;

end

end

for $\mathrm{a}=1: \mathrm{v}-\mathrm{n}$

$A(a, a+n)=-1$

$\mathrm{A}(\mathrm{a}+\mathrm{n}, \mathrm{a})=-1$

end

for $\mathrm{a}=1: \mathrm{v}$

$\mathrm{A}(\mathrm{a}, \mathrm{a})=0$;

end

seidelspectrum=eig(A)

seidelenergy=sum(abs(seidelspectrum))

\section{B. Cylinder $\mathcal{C}(\mathbf{m}, \mathbf{n})$}

The cylinder graph $\mathcal{C}(\mathrm{m}, \mathrm{n})$ is defined as the Cartesian product $P_{m} \times C_{n}$ of undirected path $P_{m}$ and an undirected cycle $C_{n}$.

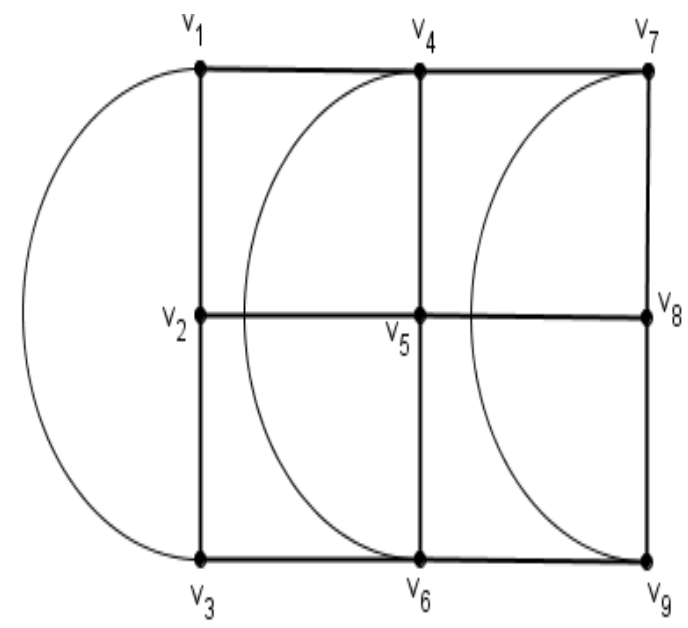

Fig 2. Cylinder(3,3)

The Seidel matrix of $\mathcal{C}(m, n)$ can be written as

Published By: 
$S=\left[\begin{array}{ccccccc}B & C & D & . & . & \ldots & D \\ C & B & C & D & . & \ldots & D \\ D & C & B & C & D & \ldots & D \\ \cdot & \cdot & . & . & . & \ldots & . \\ \cdot & . & . & . & . & \ldots & C \\ D & D & . & . & . & C & B\end{array}\right]$, where

$B=\left[\begin{array}{ccccccc}0 & -1 & -1 & . & . & \ldots & -1 \\ -1 & 0 & -1 & -1 & . & \ldots & -1 \\ -1 & -1 & 0 & -1 & -1 & \ldots & -1 \\ \cdot & . & . & . & . & \ldots & . \\ \cdot & . & . & . & . & \ldots & -1 \\ -1 & -1 & . & . & . & -1 & 0\end{array}\right]$

$C=\left[\begin{array}{ccccccc}-1 & 1 & . & . & . & \ldots & 1 \\ 1 & -1 & 1 & . & . & \ldots & 1 \\ 1 & 1 & -1 & . & . & \ldots & 1 \\ \cdot & . & . & . & . & \ldots & . \\ . & . & . & . & . & \ldots & 1 \\ 1 & 1 & . & . & . & 1 & -1\end{array}\right]$,

$D=\left[\begin{array}{ccccccc}1 & 1 & . & . & . & \ldots & 1 \\ 1 & 1 & 1 & . & . & \ldots & 1 \\ 1 & 1 & 1 & . & . & \ldots & 1 \\ . & . & . & . & . & \ldots & . \\ . & . & . & . & . & \ldots & 1 \\ 1 & 1 & . & . & . & 1 & 1\end{array}\right]$

The MATLAB program given below generates the Seidel energy of a cylinder $\mathcal{C}(\mathrm{m}, \mathrm{n})$

function energycylinder(m,n)

$\mathrm{n}=3$;

$\mathrm{m}=2$;

$\mathrm{v}=\mathrm{m} * \mathrm{n} ;$

$\mathrm{A}=$ ones(v);

for $\mathrm{a}=1: \mathrm{n}: \mathrm{v}$

for $b=a: a+(n-2)$

$\mathrm{A}(\mathrm{b}, \mathrm{b}+1)=-1$

$\mathrm{A}(\mathrm{b}+1, \mathrm{~b})=-1$

end
$A(a, a+(n-1))=-1 ;$

$\mathrm{A}(\mathrm{a}+(\mathrm{n}-1), \mathrm{a})=-1$;

end

for $\mathrm{a}=1: \mathrm{v}-\mathrm{n}$

$\mathrm{A}(\mathrm{a}, \mathrm{a}+\mathrm{n})=-1$

$\mathrm{A}(\mathrm{a}+\mathrm{n}, \mathrm{a})=-1$

end

for $\mathrm{a}=1: \mathrm{v}$

$\mathrm{A}(\mathrm{a}, \mathrm{a})=0$

end

seidelspectrum=eig(A)

seidelenergy=sum(abs(seidelspectrum))

\section{Torus $7(\mathrm{~m}, \mathrm{n})$}

The torus network $7(\mathrm{~m}, \mathrm{n})$ is defined as the Cartesian product $C_{m} \times C_{n}$ of undirected cycles $C_{m}$ and $C_{n}$.

The Seidel matrix of $7(m, n)$ can be written as

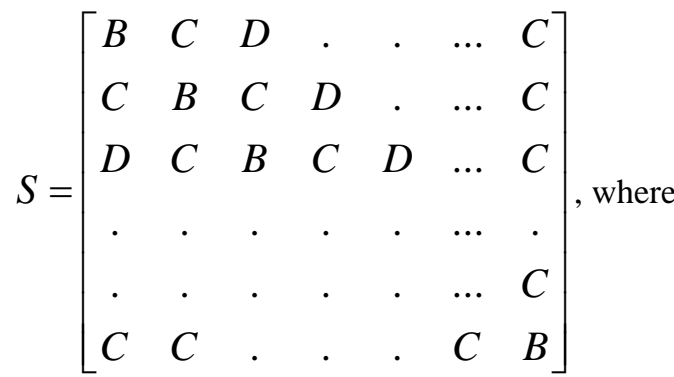

$$
B=\left[\begin{array}{ccccccc}
0 & -1 & -1 & . & . & \ldots & -1 \\
-1 & 0 & -1 & -1 & . & \ldots & -1 \\
-1 & -1 & 0 & -1 & -1 & \ldots & -1 \\
\cdot & . & . & . & . & \ldots & . \\
\cdot & . & . & . & . & \ldots & -1 \\
-1 & -1 & . & . & . & -1 & 0
\end{array}\right]
$$

$$
C=\left[\begin{array}{ccccccc}
-1 & 1 & . & . & . & \ldots & 1 \\
1 & -1 & 1 & . & . & \ldots & 1 \\
1 & 1 & -1 & . & . & \ldots & 1 \\
. & . & . & . & . & \ldots & . \\
. & . & . & . & . & \ldots & 1 \\
1 & 1 & . & . & . & 1 & -1
\end{array}\right],
$$

Published By: 


\section{On the Seidel Energy of Certain Mesh Derived Networks}

$$
D=\left[\begin{array}{ccccccc}
1 & 1 & . & . & . & \ldots & 1 \\
1 & 1 & 1 & . & . & \ldots & 1 \\
1 & 1 & 1 & . & . & \ldots & 1 \\
\cdot & . & . & . & . & \ldots & . \\
. & . & . & . & . & \ldots & 1 \\
1 & 1 & . & . & . & 1 & 1
\end{array}\right]
$$

The MATLAB program given below generates the Seidel energy of a torus $7(m, n)$.

function energytorus(m,n)

$\mathrm{n}=4$;

$\mathrm{m}=3$;

$\mathrm{v}=\mathrm{m} * \mathrm{n} ;$

$\mathrm{A}=$ ones $(\mathrm{v})$;

for $\mathrm{a}=1: \mathrm{n}: \mathrm{v}$

for $b=a: a+(n-2)$

$\mathrm{A}(\mathrm{b}, \mathrm{b}+1)=-1 ;$

$A(b+1, b)=-1$

end

$\mathrm{A}(\mathrm{a}, \mathrm{a}+(\mathrm{n}-1))=-1$

$A(a+(n-1), a)=-1$

end

for $\mathrm{a}=1: \mathrm{v}-\mathrm{n}$

$\mathrm{A}(\mathrm{a}, \mathrm{a}+\mathrm{n})=-1$

$A(a+n, a)=-1$

end

for $\mathrm{a}=1: \mathrm{n}$

$\mathrm{A}(\mathrm{a}, \mathrm{a}+(\mathrm{v}-\mathrm{n}))=-1$;

$\mathrm{A}(\mathrm{a}+(\mathrm{v}-\mathrm{n}), \mathrm{a})=-1$

end

for $\mathrm{a}=1: \mathrm{v}$

$\mathrm{A}(\mathrm{a}, \mathrm{a})=0$;

end

seidelspectrum=eig(A)

seidelenergy=sum(abs(seidelspectrum))

\section{Extended Grid EX(m,n)}

The extended grid $\varepsilon x(m, n)$ is constructed by forming every 4-cycle in a network to a complete graph. The order of $\varepsilon x$ $(m, n)$ is $m n$ and the size of $\mathcal{E} X(m, n)$ is $4 m n-3 m-3 n+2$. The following diagram (Fig.3.) illustrates the numbering chosen.

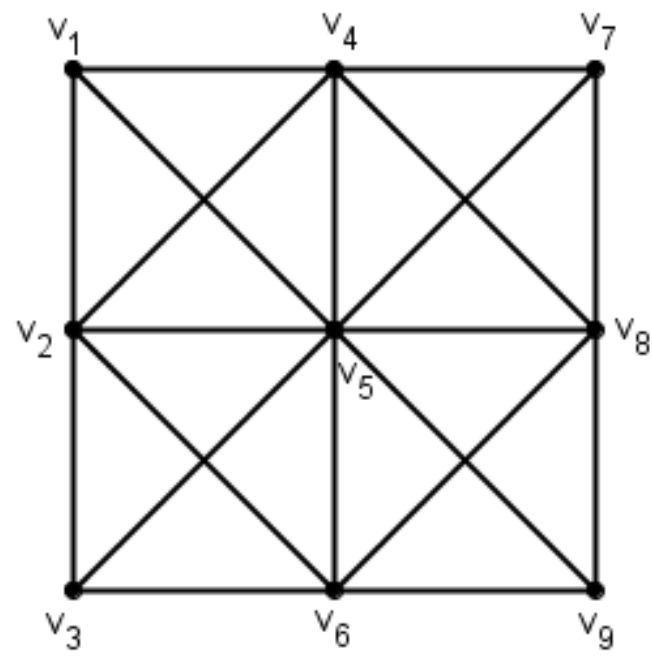

Fig 3. Extended grid $\varepsilon x(3,3)$

The general Seidel matrix of $\mathcal{E}(\mathrm{n}, \mathrm{n})$

can be written as

$S=\left[\begin{array}{ccccccc}B & C & D & . & . & \ldots & D \\ C & B & C & D & . & \ldots & D \\ D & C & B & C & D & \ldots & D \\ \cdot & \cdot & . & . & . & \ldots & . \\ \cdot & . & . & . & . & \ldots & C \\ D & D & . & . & . & C & B\end{array}\right]$, where

$B=\left[\begin{array}{ccccccc}0 & -1 & 1 & . & . & \ldots & 1 \\ -1 & 0 & -1 & 1 & . & \ldots & 1 \\ 1 & -1 & 0 & -1 & 1 & \ldots & 1 \\ \cdot & . & . & . & . & \ldots & . \\ . & . & . & . & . & \ldots & -1 \\ 1 & 1 & . & . & . & -1 & 0\end{array}\right]$

$$
C=\left[\begin{array}{ccccccc}
-1 & 1 & . & . & . & \ldots & 1 \\
-1 & -1 & -1 & . & . & \ldots & 1 \\
1 & -1 & -1 & . & . & \ldots & 1 \\
\cdot & . & . & . & . & \ldots & . \\
. & . & . & . & . & \ldots & -1 \\
1 & 1 & . & . & . & -1 & -1
\end{array}\right] \text {, }
$$

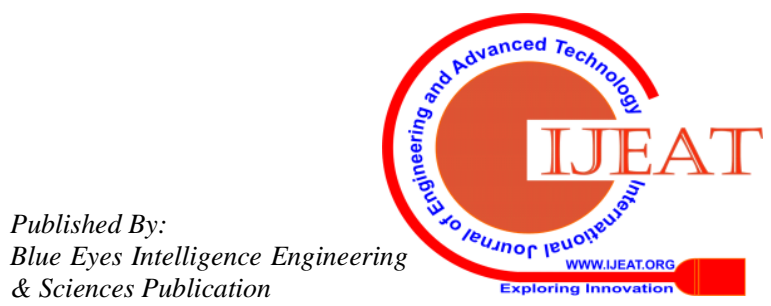




$$
D=\left[\begin{array}{ccccccc}
1 & 1 & . & . & . & \ldots & 1 \\
1 & 1 & 1 & . & . & \ldots & 1 \\
1 & 1 & 1 & . & . & \ldots & 1 \\
. & . & . & . & . & \ldots & . \\
. & . & . & . & . & \ldots & 1 \\
1 & 1 & . & . & . & 1 & 1
\end{array}\right]
$$

The MATLAB program give below generates the Seidel energy of an extended grid $\mathcal{E}(\mathrm{n}, \mathrm{n})$

function energyextendedgrid(n,n)

$\mathrm{n}=3$;

$\mathrm{v}=\mathrm{n} * \mathrm{n}$

$\mathrm{A}=$ ones $(\mathrm{v})$;

for $a=1: n: v$

for $b=a: a+(n-2)$

$\mathrm{A}(\mathrm{b}, \mathrm{b}+1)=-1$;

$A(b+1, b)=-1$;

end

end

for a=2:n:v-(n-1)

for $b=a: a+(n-2)$

$A(b, b+(n-1))=-1$;

$A(b+(n-1), b)=-1 ;$

end

end

for $\mathrm{a}=1: \mathrm{v}-\mathrm{n}$

$A(a, a+n)=-1$

$A(a+n, a)=-1$

end

for $\mathrm{a}=1: \mathrm{n}: \mathrm{v}-(\mathrm{n}+1)$

for $b=a: a+(n-2)$

$A(b, b+(n+1))=-1$;

$A(b+(n+1), b)=-1$;

end

end

for $\mathrm{a}=1: \mathrm{v}$
$\mathrm{A}(\mathrm{a}, \mathrm{a})=0$;

end

seidelspectrum $=\operatorname{eig}(\mathrm{A})$

seidelenergy=sum(abs(seidelspectrum))

\section{RESULT AND DISCUSSION}

The energy of a graph $\mathrm{G}$ is the sum of the absolute values of the eigenvalues of the adjacency matrix $A(G)$. Graphs whose energy satisfies $E(G)>2(n-1)$ are called hyperenergetic graphs. Graphs whose energy satisfies $E(G)<n$ are called hypo-energetic graphs. The aim of this paper is to determine the Seidel energy of some of the famous mesh derived networks.

1). Grid: Calculating the Seidel energy of grid using the MATLAB code generated above, we find that all the graphs are hyper-energetic.

2). Cylinder: Calculating the Seidel energy of cylinder using the MATLAB code generated above, we find that all the graphs are hyper-energetic and for $n>3$,

$\mathrm{E}(\mathscr{q}(\mathrm{m}, \mathrm{n}))<\mathrm{E}(\mathcal{C}(\mathrm{m}, \mathrm{n}))$.

3). Torus: Calculating the Seidel energy of Torus using the MATLAB code generated above, we find that all the graphs are hyper-energetic.

4). Extended Grid: Calculating the Seidel energy of Extended grid using the MATLAB code generated above, we find that all the graphs are hyper-energetic. We also find that among all the families of graphs mentioned above, the energy of extended grid is maximum.

\section{CONCLUSION}

In this paper, we have developed a procedure to calculate the eigenvalues of the Seidel matrix and hence the Seidel energy of some of the mesh derived networks.

This is of great significance in studying the characteristics of these networks in a different dimension. Finding the energy of the interconnection networks are under study. In the further research, we find the Seidel matrix for any graph.

\section{REFERENCES}

1. B. McClelland, Properties of latent roots of a matrix: The estimation of $\pi$ electron energies, J. Chem. Phys., vol. 54, 640-643, (1971).

2. Bharati Rajan, Sudeep Stephen, Albert William, Cyriac Grigorous, On Laplacian Energy of Certain Mesh Derived Networks, International Journal of Computer Applications, Vol. 55- No.11, (2012). J.Chem. phys.54, 640 - 643 (1971).

3. D.Cvetkovic, I. Gutman (eds.), Applications of Graph Spectra (Mathematical Institution, Belgrade,2009.

4. Huiqing Liu, Mei Lu and Feng Tian, Some upper bounds for the energy of graph Journal of Mathematical Chemistry, Vol. 41, No.1, (2007).

5. I. Gutman, The energy of a graph, Ber. Math. Stat. Sekt., 103(1978), 1 22.

6. I. Gutman, O.E. Polansky, Mathematical Concepts in Organic Chemistry (Springer, Berlin,1986).

7. I. Gutman,in The energy of a graph: Old and New Results,ed.by A. Betten, A. Kohnert, R. Laue, A. Wassermann. Algebraic Combinatorics and applications (Springer, Berlin, 2001), pp. 196 211. 
8. Rajesh Kanna M.R., Dharmendra B.N, Shashi R, Ramyashree R A, Maximum Degree Energy of Certain Mesh Derived Networks, International Journal of Computer Applications, Vol. 78- No.8, (2013).

9. Pradeep Kumar R, Soner Nandappa D, M. R. Rajesh Kanna, MATLAB Program to Gen- erate Harary energy of Certain Mesh Derived Networks, International Journal of Computer Sciences and Engineering, vol. 6, no. 6, (2018).

10. Willem H. Haemers, Seidel Switching and Graph Energy, MATH Commun. Math.Comput. Chem, 68 (2012), 653-659.

\section{AUTHORS PROFILE}

Sophia Shalini G.B. presently working as a lecturer at Mount Carmel college, Bangalore. She is pursuing $\mathrm{PhD}$ in Graph Theory. She is having 4 years of teaching experience.

Dr. Anwar Saleh presently working as an assistant professor at the university of Jeddah Saudi Arabia. He got his Master degree in Mathematics in September 2009 from King Abdulaziz university Saudi Arabia and his $\mathrm{PhD}$ degree in Mathematics from India. He has published more than sixty papers in national and international journals and he has around 10 papers in communication. His research interests are Algebra, Graph Theory and Design Theory.

Dr. Dhananjayamurthy B.V. presently working as an associate professor at NITTE Meenakshi Institute of Technology, Bangalore. He has done his masters and $\mathrm{PhD}$ degree from the University of Mysore, Mysore. He has published 09 papers in various national and international journals. 